\title{
GIANNI VATTIMO \\ Y LA GNOSEOLOGÍA \\ NIHILISTA NIETZSCHEANA
}

Jesús Ignacio Panedas Galindo*

\section{RESUMEN}

Gianni Vattimo es uno de los principales teóricos de la postmodernidad. Sus bases hay que buscarlas en el pensamiento heideggeriano y nietzscheano. En nuestro artículo queremos demostrar que el pensamiento nihilista que Vattimo adjudica a Heidegger y a las principales obras de Nietzsche, se encuentra, cuando menos en ciernes, en un opúsculo de juventud del autor de Rôcken titulado Sobre verdad y mentira en sentido extramoral.

\section{ABSTRACT}

Gianni Vattimo is one of the leading figures of Postmodernism with his most important influences being Heidegger and Nietzsche. This essay will demonstrate that the nihilism Vattimo attributes to Heidegger and the major works of Nietzsche can be found, at least in germ, in an early essay by the author from Röcken entitled "On Truth and Lies in a Nonmoral Sense."

\section{JUSTIFICACIÓN}

Aquí nos limitaremos a mostrar los que parecen ser los rasgos 'nihilistas' de la hermenéutica en Heidegger y a mostrar cómo, sobre la base de dichos rasgos, la 'conciencia estética', tan duramente criticada por Gadamer por considerarla ligada al subjetivismo de la filosofía de fines del siglo XIX y principios del siglo XX, queda rescatada y reencontrada como experiencia de verdad precisamente en su condición de experiencias sustancialmente nihilista (Vattimo 1998, 103).

En el libro, más arriba citado, Vattimo intenta recuperar la base nihilista del pensamiento posmoderno, que ya se encontraba en el segundo Heidegger y, antes, en Nietzsche. Los oponentes a este tipo de enfoque, como queda referido, son Gadamer y los neokantianos.

El referente inmediato de Vattimo es Heidegger. Dos son los puntos de apoyo con los que el autor italiano ilustra su afirmación. El primero de ellos hace referencia a la ausencia de fundamento del fundamento de El Ser y el Tiempo, el Dasein.

Si ello es así, la constitución hermenéutica del Dasein tiene un carácter nihilista no sólo porque el hombre se funda apartándose del centro hacia la X, sino también porque el ser cuyo sentido se trata de recuperar es un ser que tiende a 
identificarse con la nada, con los caracteres efímeros del existir, como algo encerrado entre los términos del nacimiento y de la muerte (Vattimo 1998, 108).

* Licenciado en Ciencias Religiosas, licenciado en Filosofía, maestría en Filosofía. Actualmente es el coordinador de las materias de humanidades de la Universidad La Salle, campus Pachuca. jpanedas@lasallep.edu.mx

El segundo de los puntos de apoyo es el "pensamiento rememorante" (Andenken). Esta manera de pensamiento consiste en saltar al abismo de la mortalidad, en entregarse a la libertad de la tradición. No se piensa el ser como presencia, sino solamente como ausencia. En esto consiste el nihilismo, pensar en el ser sin el ser. Se piensa lo olvidado. Se remonta a horizontes históricos fluidos para recordar el sentido del ser. Éste es el trabajo de la hermenéutica.

Para estos dos fundamentos nihilistas que Vattimo encuentra en el segundo Heidegger, ubica como predecesor al Nietzsche de la Segunda consideración inactual (1873-1876), de Humano, demasiado humano (1876-1880), y de Aurora (1881) (Vattimo 1998, 145-151). Mas cabría mencionar un ensayo que Nietzsche escribió en 1873 y que no apareció hasta después de su muerte: Sobre verdad y mentira en sentido extramoral (Nietzsche 1996, 15-38, cf. Ross 1994, 333.371.391 en adelante). En este pequeño tratado ya se asientan las bases nihilistas de la simulación vital, del lenguaje y de la moral.

Para Nietzsche el nihilismo reconoce la ausencia de todo fundamento (Vattimo 1998, 33-39). Toda relación de fundación se da en un contexto histórico de una época determinada, pero sin olvidar que las épocas son todas abiertas (Nietzsche 1997). Del ser como tal, al final, no queda nada.

En este trabajo queremos presentar las principales líneas de pensamiento de Sobre verdad y mentira en sentido extramoral y darlo a conocer como referente olvidado de esta tradición nihilista del siglo XIX 1 que tanta influencia ha tenido en los pensadores posmodernos actuales, en concreto de Vattimo.

\section{La verdad y la mentira en sentido extramoral}

Estudiar el mundo de Nietzsche implica introducirse en una crítica total y devastadora a todos los principios de su época y de la modernidad, en general. Los momentos más significativos, al mismo tiempo que los más conocidos de su reflexión son la teoría del superhombre, el eterno retorno y la muerte de Dios. Mas, toda edificación filosófica aplicada se acompaña de una teoría. Es por este motivo que la teoría del conocimiento de Nietzsche tiene relación importante con su moral y con su pensamiento completo (Habermas 1993, 37 )2.

Por este sentido de complementariedad (Habermas 1993, 32) entre las partes de Nietzsche es importante considerar su teoría del conocimiento, la cual precisa entre otros tratados, en su artículo ensayo sobre Sobre verdad y mentira en 
sentido extramoral. En este trabajo va a intentar poner al descubierto las bases morales del concepto de verdad.

Para Nietzsche el conocimiento tiene dos funciones principales: la de la simulación y la de cubrir la necesidad de ejercer el poder. Estas dos funciones responden a la necesidad principal que el hombre tiene en su vida cotidiana: proyectar un mundo de ilusiones e imágenes que aligeren la carga extrema del hombre por considerarse un ser limitado, débil y en peligro constante (Nietzsche 1996, 18).

¿Cuáles son los recursos que el intelecto humano pone en juego para complementar sus dos funciones y sus dos finalidades? En primer lugar, crea metáforas o explota su potencial de simbología (Nietzsche 1996, 44, 23)3; en segundo lugar, intenta satisfacer mediante las metáforas ciertas necesidades vitales elementales que el hombre tiene.

Sólo la ilusión objetivista de que sus interpretaciones puedan ser básicamente verdaderas y sus ficciones de conocimiento, le confieren seguridad al hombre en su tráfago vital. La verdad no es para Nietzsche una conformación entre el sujeto cognoscente y un objeto conocido, sino que cada individuo crea totalmente su realidad, según sus necesidades 4 . El error no sería más que una verdad que ya no es útil para la vida del sujeto (Copleston 1991, 322).

La verdad, ya no es algo objetivo. La realidad se ha convertido en algo inasible, en una $X$ irreconocible e inalcanzable para el sujeto.

“¿Qué es la verdad? Un ejército móvil de metáforas, metonimias, antropomorfismos, en una palabra, una suma de relaciones humanas que han sido realzadas, extrapoladas, adornadas poética y retóricamente y que, después de un prolongado uso, a un pueblo le parecen fijas, canónicas, obligatorias: las verdades son ilusiones de las que se ha olvidado que lo son..." (Nietzsche 1996, 45).

El lenguaje y su gramática es el criterio para ordenar los contenidos metafóricos (Habermas 1993, 46). La verdad se reduce, pues, a un mero deber moral que el hombre tiene que acatar si es que quiere vivir en sociedad

... pues, hasta ahora solamente hemos hablado de la obligación que la sociedad establece para existir, la de ser veraz, es decir, usar las metáforas usuales, así pues, dicho en términos morales, de la obligación de mentir según una convección fija, mentir borreguilmente en un estilo obligatorio para todos, (Nietzsche 1996, 45) 5.

A partir de todo lo dicho queda suficientemente claro que la verdad la construye el hombre según moldes antropomórficos. Le parece a Nietzsche una ingenuidad creer en la lógica férrea y estructurada de los clásicos. Esta lógica es 
un malabarismo ilusorio y conceptual del hombre a partir de su capacidad simbólica frente a los estímulos sensibles que percibe (Nietzsche 1996, 47).

Con todo lo dicho, la más urgente necesidad de la gnoseología es la de revisar la crítica trascendental de Kant desde una lógica del lenguaje. Dentro de esta dinámica las dos primeras y magníficas ilusiones del ser humano son: la existencia de un sujeto (Habermas 1993, 49; Panedas, 2006, 75-96)6 ("yo", idéntico a sí mismo) y la realidad de las cosas que se individualizan a semejanza del sujeto (se incluye también en esta categoría el principio de causalidad: existencia de una relación real entre las cosas de causa-efecto).

Nietzsche admite también la aportación necesaria de ese sujeto ilusorio en su proceso cognoscitivo de las categorías de espacio y tiempo7. Éstas, lógicamente, son también una ilusión con la que el sujeto cree acceder a las sensaciones que recibe.

De esto resulta, en efecto, que esa artística creación de metáforas con la que comienza en nosotros toda sensación presupone ya esas formas, es decir, se realiza en ellas, sólo partiendo de la firme persistencia de estas formas primordiales se explica la posibilidad de cómo, posteriormente, debió de constituirse de nuevo, desde las metáforas mismas, el edificio de conceptos. Pues éste es una imitación de las relaciones de tiempo, de espacio y de número sobre el suelo de las metáforas, (Nietzsche 1996, 49).

Esto nos puede parecer totalmente kantiano y carente de toda originalidad por parte de Nietzsche. Sin embargo, aunque trabaja sobre la estructura de Kant, Nietzsche aporta matices nuevos. Desde un punto de vista del lenguaje como norma de creación de la realidad (norma moral-social) se ubica en un plano más profundo que el kantiano (Copleston 1991, 322). La verdad ya no resulta de que estas formas a priori sean verdaderas, sino que depende totalmente de la "función necesitante del tener-por-verdadero" (Habermas 1993, 49).

¿Por qué hay que aceptar como verdaderos estos juicios sintéticos a priori kantianos? Esta sería la pregunta particular de Nietzsche. Prejuicios los hay, pero qué nos empuja a creer en ellos (no olvidar el punto de vista metafórico del conocimiento). La razón profunda está más en la línea "típica" que se conoce de Nietzsche. El deseo (voluntad) de vivir, la necesidad de mantenerse en la vida dentro de una sociedad que te impone los patrones (Habermas 1993, 50)8.

Para Nietzsche los juicios sintéticos a priori se pueden reducir a juicios morales de valor. No serían propiamente (tal y como lo defendía Kant) condiciones estructurales subjetivas que conducían a un conocimiento cierto. Más bien, hay que considerarlo como condiciones del conocimiento, que en realidad es un enmascaramiento de la realidad, al que se llega por presión social y al que tenemos que adherirnos para poder sobrevivir. En el fondo toda la teoría del conocimiento de Nietzsche está modulada por la voluntad de vivir, por la 
necesidad de conservarse en la especie mediante esa lucha por el poder (Habermas 1993, 50).

Como puede verse en lo que llevamos escrito, Nietzsche no se aparta demasiado de la teoría kantiana (Habermas 1993, 51). Sigue por sus mismas huellas. Lo que sí hace es profundizar más en cómo conocemos y en cómo elaboramos nuestros conceptos partiendo de la necesidad de conservar la existencia y la vida en medio de un mundo o sociedad que lucha a muerte por mantenerse en el poder9.

La conclusión a la que llegamos es el nihilismo. No existe un mundo verdadero. Lo verdadero se reduce a lo subjetivo que cada ser se fabrica. Ya no tiene sentido para Nietzsche una realidad objetiva, una norma moral de acuerdo a la cual comportarse (el hombre está inclinado a conservarse en la vida, esa es su finalidad inmediata). Se destruye el concepto clásico de hombre conducido según la razón hacia lo que considera su bien mayor. Es la caída total de lo que ya decíamos al principio de este ensayo, de la cultura moderna y clásica. Al destruirla deja al hombre suspenso en la nada, que además vuelve a repetirse por los siglos de los siglos.

Desde este pensamiento no es difícil derivar hacia un pragmatismo vital (Copleston 1991, 323; Rorty 1997, 43-76) (hago conforme lo que me conviene para salir beneficiado yo) o en un indiferentismo total fundamentado en la subjetividad engañosa de cada quien.

\section{Crítica somera a la teoría del conocimiento de Nietzsche}

Después de todo lo visto se le podrían hacer dos críticas a Nietzsche. Una primera es la inconsecuencia dentro de su pensamiento respecto a Kant. Nietzsche no acepta en ningún momento la moral pietista de Kant. El imperativo categórico kantiano choca de frente contra toda la teoría nietzscheana de la voluntad de poder. Pero, por otra parte, Nietzsche admite prácticamente al pie de la letra su teoría del conocimiento. Todo tiene su consecuencia. La teoría del conocimiento siempre influye o conlleva unas conclusiones para la moral. Es por eso que Nietzsche intenta modificar los juicios sintéticos a priori desde la subjetividad vital de la conservación para darle un tinte nuevo a su pensamiento, pero no logra separarse del influjo kantiano. Su enfoque desde el punto de vista del lenguaje y de los juicios de valor no lo hacen radicalmente distinto a Kant.

La segunda crítica que se le puede hacer es la siguiente. Nietzsche defiende un subjetivismo absoluto respecto a la verdad. Siempre va a ser una mentira construida por el hombre para satisfacer sus necesidades. Pero la conclusión a la que llega es una afirmación absoluta de que la verdad no existe. Esta aseveración en sí misma es una verdad absoluta. Nietzsche no puede decir que ella es también una falsedad o una creación de su mente. Si esto afirmara querría decir que después de tanto pensar y analizar el conocimiento no habría llegado a 
ninguna conclusión. Sería un nihilismo gnoseológico, acorde, por otra parte, con su nihilismo vital (Copleston 1991, 322)10.

\section{CONCLUSIÓN}

Posiblemente en Sobre verdad y mentira en sentido extramoral no aparezcan términos (Dasein, Andenken...) que Heidegger considerara necesarios para fundamentar el nihilismo que postuló en la segunda etapa de su vida. Quizá el ensayo que nos ha ocupado en nuestro trabajo no haya sido muy estudiado. Quizá no sea de las principales obras de Nietzsche... pero sí, tras el estudio realizado, podemos concluir que el nihilismo, la simulación del lenguaje, la necesidad de ocultar la realidad mediante metáforas... dirigen el pensamiento nietzscheano desde sus comienzos hacia un nihilismo que tanto influirá en Heidegger como en la posmodernidad.

Vattimo no profundiza, ni menciona, la importancia de este ensayo que nos ha ocupado. Empero pareciera que es imprescindible para mencionar las raíces nihilistas del pensamiento del siglo XX y XXI. La gnoseología de Nietzsche ofrece los pies originales del nihilismo moral, epistemológico y vital. Desde este ensayo del primerísimo Nietzsche aparecen algunas ideas esenciales que posteriormente conformarán el bloque de su pensamiento. Entre ellas está el nihilismo que a Vattimo tanto le interesa.

\section{NOTAS}

1 El prototipo de nihilista descreído de finales del siglo XIX y principios del siglo XX puede ser Iván Karamazov (Phillips 1997, XX-XXIV). En él caracterizamos toda la corriente literaria rusa que pudiera servir para mantener la presencia de la nada en el pensamiento de los dos autores alemanes.

2 Sobre este estudio de Habermas vamos a fundamentar los comentarios sobre la gnoseología de Nietzsche.

3 El esquema de Nietzsche en su teoría del conocimiento es el siguiente: primeramente, el hombre recibe una sensaciones, las cuales son traducidas a imágenes, que posteriormente, se convierten en conceptos (moldes que igualan lo no-igual). Este proceso nos da la forma y el concepto, siendo así que en la naturaleza no existen ni conceptos ni formas, sino una $\mathrm{X}$ desconocida.

4 Esta objetivación es la diferencia entre los animales y el hombre. El hombre es el animal mentiroso por excelencia a partir de su capacidad de elaborar metáforas a las que les da el valor consuetudinario de verdad, aunque sean pura fabricación consensuada de realidades. Todo este castillo de naipes es edificado con la única finalidad de tener poder. Estos recursos de autodefensa no se dan entre los ani males, los cuales no disponen de esta racionalidad ni de esta necesidad de autoengañarse para poder sobrevivir. 
5 Ésta va a ser la gran diferencia con la teoría del conocimiento de Kant. La moralidad se convierte en el criterio de verdad y no la construcción propia que se da entre la sensación y las formas o categorías de los juicios sintéticos a priori de Kant. La verdad es un consenso social, es decir, una mentira (elabo ración conceptual) que consensuada se convierte en verdad.

6 Hay matices diferentes entre Nietzsche y Kant, aunque aquél no supere a éste, sino que le da una mayor profundidad.

7 En este punto Nietzsche es fiel seguidor de Schopenhauer en su teoría del conocimiento, con la sal vedad de que éste incluye en las formas a priori de la sensibilidad a la causalidad, que para Kant era una categoría más.

8 Es curioso el contraste con el pensamiento de Schopenhauer que consideraba al impulso vital como lo más falso del instinto de conservación del hombre que estaba condenado, como nada que era frente al no-existir, al desaparecer. Nietzsche es el defensor de la voluntad de vivir como una pulsión instintiva que obliga al hombre a luchar por su sobrevivencia con la seguridad de que la historia ha de volver a repetirse. El hombre no desaparece en la nada (Schopenhauer), sino que está anclado en un eterno retorno del tiempo que conduce a la nada (nihilismo de Nietzsche).

9 Cuando hablamos de mantenerse en el poder no nos referimos únicamente en el poder militar o político o cualquier otro, sino en general, en tener imperio sobre los demás miembros de la humani dad para poder perpetuarse en la existencia. En definitiva, se podría hacer referencia a la necesidad de llegar a la "moral del señor" y evitar la "moral de siervo". Suenan, también, de fondo notas pare cidas a las que Wagner incluyera en sus trilogías arias. En ellas se defiende las tradiciones germanas.

"Ahora la idea básica de su nuevo libro aparecía con total claridad ante él: nacimiento de la tragedia del espíritu de la música dionisiaca; muerte de la tragedia por el espíritu del socratismo; renacimiento de la tragedia del espíritu del germanismo y de la música de Richard Wagner... Así, pues, el libro no debía terminar con un homenaje, una apoteosis, sino con un análisis crítico del presente, de modo que condujera de manera totalmente espontánea a Wagner como salvador... el señuelo dionisiaco era perfectamente conocido de todos los amigos de Wagner por su Siegfried", (Ross, 1994, 308-311).

Todo esto puede concluir en la teoría del "superhombre", mitad nietzscheana y no del darwiniana, que más tarde será mal usada por el nacionalsocialismo hitleriano.

10 Sería la misma crítica que se les dirige a la corriente escéptica.

\section{REFERENCIAS}


COPLESTON, Frederick (1991), Historia de la Filosofía 7. De Fichte a Nietzsche, México: Ariel.

HABERMAS, Jürgen (1993), Sobre Nietzsche y otros ensayos, México: REl.

NIETZSCHE, Friedrich, (1996), Sobre verdad y mentira en sentido extramoral, en F. NIETZSCHE-Hans

VAIHINGER, Sobre verdad y mentira, Madrid: Tecnos.

-, (1997) Fatum e historia, ID., De mi vida. Escritos autobiográficos de juventud (1856-1869), Madrid: Valdemar.

PANEDAS, Jesús Ignacio (2006), Idemidad o ipseidad, identidad o anihilamiento, Logos XXXIV.

PHILLIPS, Rosa María (1997), Prólogo, en Fedor M. DOSTOIEVSKI, Los hermanos Karamazov, México: Porrúa

RORTY, Richard (1997), ¿Esperanza o conocimiento? Una introducción al pragmatismo, Buenos Aires: Fondo de Cultura Económica.

ROSS, Werner (1994), Friedrich Nietzsche. El águila angustiada. Una biografía, Barcelona: Paidós.

VATTIMO, Gianni (1998), El fin de la modernidad. Nihilismo y hermenéutica en la cultura posmoderna, Barcelona: Gedisa 